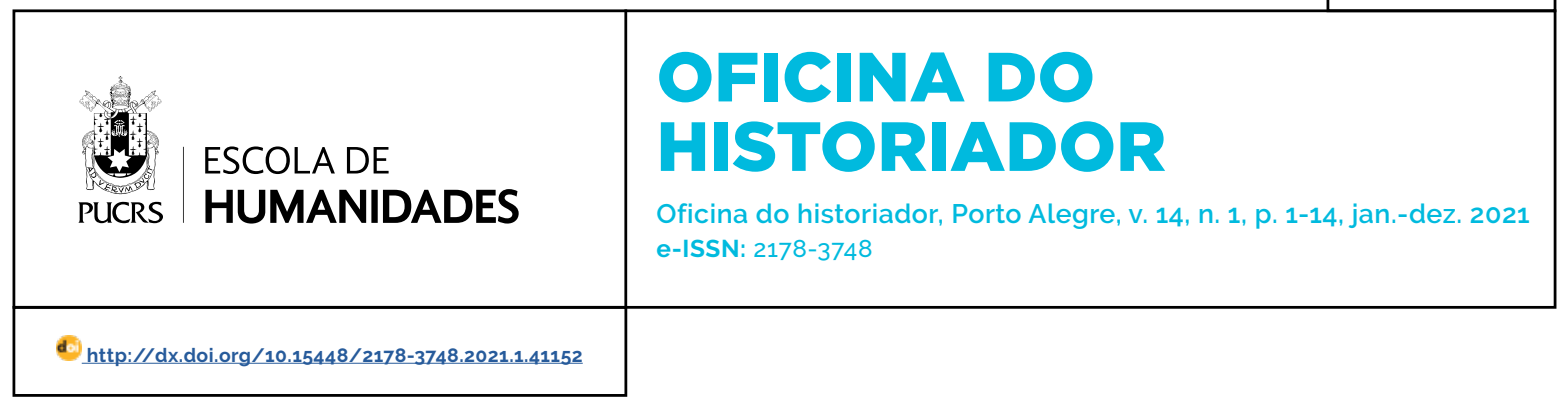

SEÇÃO: ARTIGOS

\title{
Diálogos quanto aos conceitos relacionados ao tempo
}

\author{
Dialogues regarding concepts related to time
}

\section{Cristina de Cássia \\ Pereira Moraes ${ }^{1}$}

orcid.org/0000-0001-8767-7070 cristinadecassiapereiramoraes@ gmail.com

\section{João Ferreira Sobrinho Junior $^{1}$}

orcid.org/0000-0003-3756-9797 joffersoju07@hotmail.com

Recebido em: 20 jun. 2021. Aprovado em: 19 ago. 2021. Publicado em: 03 nov. 2021.

\section{(c) (1)}

Artigo está licenciado sob forma de uma licença Creative Commons Atribuição 4.0 Internacional.
Resumo: A discussão da temporalização no interior dos discursos históricos nos apresenta dentre outras matizes, os conceitos que a orbitam. Nesse sentido, propor um diálogo mais profundo sobre essa questão, pode contribuir como base teórica para estudantes, pesquisadores e amantes da história, no debate, na reflexão e na problematização dos modos de se conceber a temporalização dessa. Desse modo, este artigo tem por objetivo discutir conceitos relacionados ao tempo. Para responder a tal cenário se dispôs de pesquisa documental e bibliográfica, as quais se basearam em artigos científicos, livros, dissertações, teses, sites da web, dentre outras fontes, para o levantamento, a coleta e a análise dos dados de forma qualitativa. E como resultado, dialogamos por três características que são correlacionadas ao tempo: temporalidade, duração e processo histórico. Em relação a primeira, que é a temporalidade, essa se perfaz através da percepção humana do compreender a conexão temporal existente entre o passado, o presente e o futuro. A segunda se estabelece pela duração, dessarte, consideramos que essa não se regula no tempo cronológico e sim, seu entendimento subjetivo é relativo ao movimento e à permanência do atual para o novo. A terceira característica é o processo histórico, o qual se pauta no conjunto das sucessões dos eventos históricos. No entanto, há de se destacar que em torno do processo histórico gravitam conceitos relevantes como: evento/ fato histórico; devir; e, continuidades e rupturas. Esses conceitos, se apresentam de forma complementar, mas ao mesmo tempo antagônicos, e se digladiam entre si no campo de estudo de cada atividade humana ou mesmo entre elas. Logo, percebemo-los como dialeticamente unidos em um fluxo ao qual se estabelecem como força motriz do próprio movimento da história. Conclui-se, então, que ao se discutir acerca dos conceitos que orbitam a questão do tempo, se permite o alargar do arcabouço teórico para uma geração de historiadores que se formaram alheios à reflexão mais consistente sobre a temporalização no interior dos discursos históricos.

Palavras-chave: Tempo. História. Processo Histórico.

Abstract: The discussion of temporalization within historical discourses presents us, among other nuances, the concepts that orbit it. In this sense, proposing a deeper dialogue on this issue can contribute as a theoretical basis for students, researchers and history lovers in the debate, reflection and problematization of the ways of conceiving the temporalization of history. Thus, this article aims to discuss concepts related to time. In order to respond to this scenario, we used a documental and bibliographic research, which was based on scientific articles, books, dissertations, theses, websites, among other sources, for the survey, collection and analysis of data in a qualitative way. As a result, we dialogued on three characteristics that are correlated to time: temporality, duration, and historical process. In relation to the first, which is temporality, this is made through the human perception of understanding the temporal connection existing between past, present, and future. The second is established by duration, therefore, we consider that this is not regulated by chronological time, but rather, its subjective understanding is relative to the movement and permanence from the present to the new. The third characteristic is the historical process, which is based on the succession of historical events. However, it should be noted that around the historical process gravitate relevant concepts such as: historical event/fact; becoming; and, continuities and ruptures. 
These concepts are complementary, but at the same time antagonistic, and they fight among themselves in the field of study of each human activity or even among them. Therefore, we perceive them as dialectically united in a flux in which they are established as the driving force of the very movement of history. We conclude, then, that when discussing about the concepts that orbit the issue of time, it allows the widening of the theoretical framework for a generation of historians who were formed without a more consistent reflection on temporalization within the historical discourses.

Keywords: Time. History. Historical Process.

\section{Introdução}

A história humana se desenrola no tempo a partir de ações ativas e passivas, onde o teatro é formado pelo mundo em que vivemos e os atores são os homens (sujeito) que podem efetivamente realizar as ações por si mesmos ou indiretamente através de outros atores naturais que constrangem a fazê-lo. Isto posto, o tempo a priori não poderia ser concebido abstratamente se não fosse pensado a partir de um olhar ativo do sujeito, que é o homem. Nesse sentido, o próprio tempo influencia esse sujeito e a forma que eles se veem com o passar das épocas.

O diálogo sobre o tempo e seus conceitos, é uma problemática atual e necessária que entremeia questões as quais esse sujeito que é o homem, põe à luz. E dentre esses conceitos constituidos, destacamos a temporalidade, a duração e o processo histórico. No primeiro caso, a temporalidade, está ligada à forma na qual se compreende a conexão relacional entre o passado, o presente e o futuro. O segundo caso se refere à percepção que se tem da duração do tempo, sob diferentes formas ou contextos, sejam eles individuais ou coletivos. E, por fim, o processo histórico que se estabelece com base em um conjunto de eventos ou fatos históricos reunidos em torno de um contexto, muito embora a multiplicidades de contextos de variados campos da atividade humana pode se entrelaçar a partir de acontecimentos principais de determinada sociedade. É preciso destacar, também, que o processo histórico é um conjunto comple$\mathrm{xo}$, composto por elementos conceituais que $\mathrm{o}$ orbitam, como: evento/fato histórico; devir; e, continuidades e rupturas.
O estudo acerca de conceitos relacionados ao tempo é uma temática que direta ou indiretamente, autores como Bloch (2001), Rahmeier (2020), Santo Agostinho (1955), Borges (1987), Martins (2004), São Tomás de Aquino (1977), Koselleck (2006), Hartog (2015), Galileu Galilei (1988), René Descartes (1997), Isaac Newton (1990), Albert Einstein (2008), Immanuel Kant (1980), Henri Bergson (2004), Elias Norbert (1998), Gaston Bachelard (2007) dentre outros, já realizaram pesquisas ou reflexões sob múltiplos aspectos. Dessa forma, percebe-se a relevância e a pertinência do tema para os mais variados campos da atividade humana, como o sociológico, filosófico, histórico, matemático etc. A razão para tal se faz presente devido à gama de ramificações que podem irradiar desse objeto de estudo.

O percurso metodológico dessa pesquisa se baseará na abordagem qualitativa sob viés documental e bibliográfico. Esses dois modos de se pesquisar se assemelham, mas se diferenciam devido à natureza da fonte de busca, pois Gil (2002) discorre que, enquanto na pesquisa documental não há um olhar avaliativo sobre o seu conteúdo, como por exemplo em cartas, diários, ofícios, sites, redes sociais, dentre outras, ou seja, são constituídas por fontes primárias, a pesquisa bibliográfica, já possui uma revisão quanto ao seu conteúdo, e nela destacam-se artigos, teses, monografias, livros, dentre outros, ou seja, são fontes secundárias.

No que se refere à coleta, análise e discussão dos dados, em princípio, levantamos autores que discutem o tempo sob os aspectos do homem (sujeito). Além disso, investigamos características que permeiam a duração, temporalidade e processo histórico, no interior dos discursos históricos concernentes ao tempo. Ademais, discorremos sobre conceitos que consideramos orbitar mais efetivamente o processo histórico como o devir, evento/fato histórico e as continuidades e rupturas, com fins a alcançarmos o objetivo desta pesquisa.

O objetivo deste artigo é discutir conceitos relacionados ao tempo. Dessarte, uma vez que esta é uma temática que vem sendo estudada 
há um longo periodo, torna-se relevante esse olhar sobre o objeto em questão. Em vista a isso, consideramos que abrir diálogo que tome por base essa perspectiva na qual diversos campos da atividade humana se entrelaçam, pode trazer contribuições em pesquisas, debates e reflexões por estudantes e pesquisadores da história, tanto em aspectos teóricos quanto empíricos que se fundamentam nesse objeto.

\section{O sujeito e o tempo: questões intrínsecas}

O que é o tempo? Essa é uma questão que permeia tanto conversas informais em bares quanto em rodas de intelectuais, pois muito embora o tempo seja algo abstrato ele influencia diretamente todo o mundo em que vivemos, tanto no sentido cronológico quanto histórico. Nesse cenário, o homem é um fator preponderante pois ele é o ser racional que busca compreender esse objeto.

O próprio homem é um ser de mudança, o sujeito imprescindivel para fazer girar a roda da história na qual o tempo é um dos grandes atores. Esse mesmo tempo faz com que o sujeito homem, através dos séculos, passe a se ver sob conceitos variados por conta das percepções em sua concepção temporal de se pensar história. Nota-se tais mudanças conceituais, passando da antiguidade pela História Magistra Vitae - tempo dos heróis ao Pós-Modernismo contemporâneo - onde um simples individuo pode ser construtor da história -, muito embora essas concepções de história ainda se entrelacem nos objetos de pesquisa pelos historiadores. Enfim, para exemplificar essas mudanças de conceito de sujeito na história, o poema de Brecht (2006) é uma boa referência ao citar não apenas os atores principais, mas também, os indivíduos que contribuíram em seus pequenos papéis nas grandes aventuras e batalhas.

\section{Perguntas de um Operário que Lê}

Quem construiu Tebas, a das sete portas?

Nos livros vem o nome dos reis,

Mas foram os reis que transportaram as pedras?

Babilónia, tantas vezes destruida,

Quem outras tantas a reconstruiu?
Em que casas da Lima Dourada moravam seus obreiros?

No dia em que ficou pronta a Muralha da China para onde

Foram os seus pedreiros?

A grande Roma

Está cheia de arcos de triunfo.

Quem os ergueu?

Sobre quem Triunfaram os Césares?

A tão cantada Bizâncio

Só tinha palácios para os seus habitantes?

Até a legendária Atlântida

Na noite em que o mar a engoliu

Viu afogados gritar por seus escravos.

O jovem Alexandre conquistou as Índias,

Sozinho?

César venceu os gauleses.

Nem sequer tinha um cozinheiro ao seu serviço?

Quando a sua armada se afundou Filipe de Espanha

Chorou. E ninguém mais?

Frederico Il ganhou a guerra dos sete anos,

Quem mais a ganhou?

Em cada página uma vitória.

Quem cozinhava os festins?

Em cada década um grande homem.

Quem pagava as despesas?

Tantas histórias

Quantas perguntas

(BRECHT, 2006, p. 144)

O que podemos denotar desse poema? A principio nota-se coisas cotidianas que são desempenhadas por individuos simples ante a grandes vitórias, conquistas suntuosas de reis e soberanos poderosos. Assim, o pensar histórico de sujeito mudou da antiguidade aos dias de hoje passando pelos Annales, pois quem antes era esquecido, passou a ser e se fazer construtor e pertencente ao processo histórico, onde o sujeito é ser pensante e realizador das ações no tempo e no espaço em que vive.

Portanto, o conceito de sujeito mudou com o tempo, não que os individuos anônimos teoricamente não seriam partícipes do processo histórico, mas para que assim o fosse, deveria ser um 
homem/mulher de renome onde se depositaria uma fonte exemplar para a sociedade e para o futuro. Tal pensamento fora desmistificado a partir da Escola dos Annales em que todos passam a ser partícipes e integrantes do processo histórico, e assim sujeitos históricos. Desse modo, o estudo da história passa a ser (re)configurado e o historiador deixaria de apenas ver o passado e os homens valorosos como fonte da história. Nesse contexto, Bloch conceitua a história como a ciência dos homens do tempo, pois "dificilmente imagina-se que uma ciência, qualquer que seja, possa [se] abstrair do tempo" (2001, p. 55).

Em uma percepção do senso comum, costumeiramente o tempo tende a ser pensado no sentido cronológico. Este modo de se conceber o tempo, parte de medidas estabelecidas em unidades quantificáveis e entrelaçadas como segundos, minutos e horas, configurando-se assim, uma forma linear. Nesse sentido, identifica-se uma divisão clara entre o passado, o presente e o futuro, de forma subsequente, na qual esse movimento progressivo confirma a artificialidade do tempo cronológico pois este estaria submetido ao espaço (BARROS, 2010). Assim, podemos notar que o tempo cronológico é predominantemente linear e engessado nas concepções de passado, presente e futuro, onde mesmo que possam se entrelaçar, não se confundem.

Diferentemente do tempo cronológico, o tempo histórico se baseia na análise e na compreensão dos eventos dos sujeitos. No tempo histórico não se delimita em se conhecer a sequência dos fatos, mas a interrelação, duração, simultaneidade, sucessão, permanência e ruptura dos fatos, pois isto faz parte da construção do processo do tempo ao qualé essencial à formação humana. Nesse sentido, os professores "de história precisam se preocupar com as diferentes concepções de tempo, para não construirem processos de aprendizagem onde apenas os fatos sejam os únicos tipos de conhecimento que os alunos tenham acesso" (RAHMEIER, 2020, p. 7). Logo, o tempo histórico pode ser pensado de forma regionalizada, contextualizada em determinada área da atividade humana ou mesmo que englobe toda a humanidade.
Observa-se então que não existe relação fixa de concordância temporal entre o cronológico e o tempo histórico, tendo em vista, por exemplo, que determinado povo ou região pode vivenciar distintos tempos históricos dentro de um mesmo contexto cronológico. Por consequência, consideramos que o tempo cronológico não impôs aguilhões na história, ou seja, ela não é sua prisioneira e, por conta disso, o próprio oficio do historiador depõe em um contínuo andar entre o passado, o presente e o futuro, com as perspectivas de encontrar as respostas para o objeto que está sendo pesquisado.

Sendo pela ideia de tempo cronológico ou histórico, a percepção de tempo no decorrer da história perpassou sob vários aspectos, formas e magnitudes, desde muitos séculos antes de Cristo como nos escribas akkadianos citado por Barros (2011) em que relatavam conquistas e realizações mesopotâmicas nos tempos da dinastia de Akkad. Nota-se que o tempo já se encontrava incrustado no pensamento humano desde há muito, e com o passar dos séculos este passa a ser crucial nos estudos históricos.

Isto posto, temos que nos dias de hoje, o tempo é tema recorrentemente discutido sob vários aspectos e campos da atividade humana, como na física, na biologia, na sociologia, na história, dentre outros. De tal modo, se torna relevante perfazermos o resgate desse conceito perante essa multiplicidade de áreas e em contextos temporais diversos, tendo em vista sua polissemia. Sendo assim, a começar pela antiguidade no pensar filosófico e teológico adotado por autores como Platão (1981), Aristóteles (MARTINS, 2004), Plotino (1987), Santo Agostinho (1955) e São Tomás de Aquino (1977).

No Timeu, Platão (1981) disserta sobre sua percepção cosmogônica sobre o tempo. Essa sua percepção considera que o tempo fora concebido pelo divino, tal qual, como uma representação limitada e móvel da eternidade que "progride segundo a lei dos números" (PLATÃO, 1981, p. 92).

Outro autor histórico que traça ponderações sobre o tempo é Aristóteles. Em seu pensamento ele delineia diferenças entre a mudança e o tempo, pois enquanto a mudança permitiria 
movimento e alterações, o tempo seria imutável, continuo, infinito e eterno. Ou seja, se não houvesse mudança não havia percepção do tempo, tendo em vista que só se tem a percepção do tempo, através das mudanças que ocorrem, a partir da comparação do antes e o depois. Nesse sentido, a ideia de continuidade em Aristóteles, está relacionada com espaço, com o movimento e com o tempo (MARTINS, 2004).

Em relação ao pensamento de Plotino, Borges (1987) descreve que não é preciso que algo seja mensurável para que exista, assim, mesmo que não se possa medir a duração de algo, não quer dizer que não exista. Dessa forma, Plotino considera três tipos de tempo: o primeiro é o atual no qual eu falo, que a partir do momento dito, já se torna passado; o segundo é o que já é pertencente ao passado e que se põe sob a memória; e, por fim, o futuro, que vem a ser o que se imagina acontecer, por esperança ou medo.

Santo Agostinho (1955) também discorreu sobre o tempo. Em sua percepção arguiu da complexidade de se afirmar e estabelecer o seu conceito. No entanto, ao considerar que há uma mudança ao qual os fatos vão e vem, acontecem e se sucedem, ele afirma que há o passado, o presente e o futuro. Portanto, ao considerar o tempo presente, esse invariavelmente se tornará ao passado, tornando sua existência fugaz pois sua própria razão de existir é deixar de existir ao ser levado ao passado e, por isso, "o que nos permite afirmar que o tempo existe é a sua tendência para não existir" (1955, p. 120). Seu pensamento sobre o tempo, também discorre sobre sua duração e sobre o que é passado, presente e futuro no contexto de tempo. Pois, logo, se pudéssemos conceber uma divisão subsequente e diminuta do tempo, por menores que sejam, teríamos cada fração sendo o tempo presente em determinado momento, mas "sua passagem do futuro para o passado seria tão rápida, que não teria nenhuma duração. Se a tivesse, dividir-se-ia em passado e futuro, mas o presente não [existiria] em duração alguma" (AGOSTINHO, 1955, p. 121).

Outro religioso, São Tomás de Aquino (1977) foi crucial na harmonização dos pensamentos helênicos com as doutrinas da igreja católica nos tempos do medievo. Sobre sua compreensão do tempo em um sentido do Sagrado, ele diz que sem Deus não há sucessão do tempo. Nesse direcionamento, o tempo somente age sobre os seres que estão sujeitos ao movimento de sucessão do tempo, sendo este caminho apenas percorrido unidirecionalmente, do passado para o futuro, e assim, em Deus não é possivel o tempo incidir pois "todo o seu ser existe simultaneamente" (AQUINO, 1977, p. 13-14).

A partir do final do medievo com o advento do Renascimento, encontramos outros autores que também se perfilaram em demonstrar a existência e relações entre o tempo e o mundo físico, como podemos citar no campo das exatas (matemática, física e química): Galileu Galilei (1988), René Descartes (1997), Isaac Newton (1990) e Albert Einstein (2008). Além de filósofos como Immanuel Kant (1980), Henri Bergson (2004), Elias Norbert (1998) e Gaston Bachelard (2007).

No campo das exatas iniciaremos por Galileu Galilei (1988). Este cientista inseriu de forma incisiva a questão do tempo na Lei da Queda dos Corpos - utilizada posteriormente como base de pesquisa em Newton e Einstein. Nesse estudo, ele relaciona a estrita afinidade que há entre o tempo e o movimento, ao descrever que a uniformidade do movimento se concebe pela igualdade do tempo e do espaço percorrido, pois "concebemos no espírito que um movimento é uniforme e, do mesmo modo, continuamente acelerado, quando, em tempos iguais quaisquer, adquire aumentos iguais de velocidade" (GALILEI, 1988, p. 160).

Outro cientista a ser citado é René Descartes, que dentre as pesquisas que realizou destacamos os trabalhos relativos ao universo e a inércia. No que concerne aos seu pensamento sobre o tempo, é dito por Piettre (1997) que a duração do tempo é distinta para as coisas que duram de forma física e aquelas nas qual é utilizado o tempo por medida numérica que existem de "modo ideal em nosso espirito, independentemente das coisas que duram" (PIETTRE, 1997, p. 92).

Também citaremos Isaac Newton (1990) que foi um dos grandes pesquisadores da matemática 
e da física. Acerca de sua percepção de tempo, em sua obra Principia: Princípios Matemáticos da Filosofia Natural, ele o divide em: absoluto, verdadeiro e matemático - no qual o tempo existe por si mesmo em sua própria natureza sem sofrer influência externa; e, relativo, aparente e comum - na qual se utiliza algum tipo de medição perceptivel que "é obtida através do movimento e que é normalmente usada no lugar do tempo verdadeiro, tal como uma hora, um dia, um mês, um ano" (NEWTON, 1990, p. 7).

Albert Einstein, físico renomado do século $X X$, também apresentou sua percepção de tempo, a partir de suas leis da relatividade. No pensamento de Einstein, o tempo é relativo e assim, o que se é observado é a parte da leitura individual de cada um, como indica Ghisolfi (2008) de que o tempo em Einstein passa a ser entrelaçado com o espaço ao qual o indivíduo está presente. Isso se exemplifica na descrição de um cenário hipotético, ao qual se imagina que, se dois relógios estiverem se deslocando em grande velocidade através do espaço, estes passam a conceber o tempo de forma mais devagar. Sob esse olhar de Einstein "o tempo agora passa a ser visto como elástico e depende [de] um espaço, que de modo semelhante se deforma" (GHISOLFI, 2008, p. 33).

No campo da filosofia vamos começar com Immanuel Kant (1980). Sobre ele, podemos citar sua cosmovisão baseada nas leis de Newton e que suas obras orientaram a filosofia alemã moderna. Acerca de sua perspectiva sobre o tempo, este o considera como uma representação a todas as intuições, pois afeta os fenômenos físicos, muito embora, esses mesmos fenômenos não podem afetar ao tempo em si. Logo, o tempo é uma intuição interna do sujeito que o atribuiu, pois, se a "condição particular da nossa sensibilidade lhe for suprimida, desaparece também o conceito do tempo, que não adere aos próprios objetos" (KANT, 1980, p. 45).

Também destacaremos o pensamento Henri Bergson, o filósofo do devir. Seus ensaios sobre a consciência, matéria e memória, lhe renderam o Nobel de Literatura em 1927. Segundo Coelho (2004), Bergson considera o tempo como fun- damental em seus pensamentos, pois ele é um filósofo do tempo. Em seus estudos ele destaca a necessidade de se pensar o tempo real, e como elementos essenciais deste tempo real, pontua a "sucessão, continuidade, mudança, memória e criação" (COELHO, 2004, p. 234).

Ainda no campo social e filosófico, realçaremos o pensar de Elias Norbert sobre o tempo (1998). Em suma, para ele o tempo em si próprio não existe, mas passa a sê-lo por ser um símbolo social. Nesse sentido, o tempo para o autor foi criado a partir de marcos integrados de reguladores temporais como no caso do relógio, calendários e das eras que se sucederam na história humana, pois "quando faltam instrumentos [de medição], essa experiência do tempo também fica ausente" (NORBERT, 1998, p. 36).

E por fim, citaremos Gaston Bachelard (2007) que fundamentou seus estudos prioritariamente em aspectos da filosofia da ciência. Acerca de sua perspectiva sobre o tempo, discorre que a consciência do tempo é uma consciência ativa de usufruto desse tempo, em suma expõe que "a consciência de nossa duração é a consciência de um progresso de nosso ser íntimo, seja de progresso efetivo, imitado ou, ainda, simplesmente sonhado" (BACHELARD, 2007, p. 86). Assim, percebe-se que para ele, a existência do conhecimento do movimento do tempo é ativada através da consciência, que faz essa ligação passado-futuro.

Portanto, a partir desses pensamentos provindos de vários campos da atividade humana, percebemos diversas questões nas quais o tempo é pensado, concebido e debatido, o que denota assim, sua importância. Por fim, temos a realçar que a partir do controle do tempo pelo relógio de sol ou mais recentemente relógios manuais e digitais, os luminares perderam o juizo de guardiões do tempo pois estes estariam agora na palma da mão, onde as atividades humanas se concentram no estrito passar das horas contadas, no tic-tac. Nesse contexto, a vida cotidiana não poderia resistir a essa maravilha cronometrada que aprisiona o homem, mas que o liberta ao mesmo tempo. Então, a partir desse controle. dividido estaria a hora de pastorear, de buscar água na fonte e das festas da vida social, como 
também as rotinas sagradas seguiriam esse caminho, do batismo passando pelo casamento até a extrema unção, tudo de acordo com o seu devido tempo (BÍBLIA, 2020). Logo, o tempo passa a ser mecanizado, roteirizado e disciplinado, onde ser desocupado não teria espaço, pois o tempo não pode ser desperdiçado. E, assim, ele é um eterno devir, de onde sucessões de fatos, iniciam e se descontinuam, em que aparecem ou somem, entrelaçando o passado, presente e o futuro.

\section{Um olhar sobre o tempo e seus conceitos}

O tempo é pensado e descrito sob diversas nuances, de acordo com o campo ao qual está sendo observado ou mesmo de acordo com cada autor em específico, porém consideramos que há questões sobre o tempo que permeiam essas multiplicidades de pensamentos, aos quais podemos identificar como conceito, ideia, noção, concepção etc. Enfim, nesse sentido, ponderamos alguns termos correlacionados ao tempo, com a finalidade de melhor compreendê-los, aos quais são:
a) temporalidade;
b) duração;
C) processo histórico.

O primeiro ponto trata da temporalidade. Acerca desse conceito Barros (2014) concebe que a temporalidade só adquire sentido através da percepção humana e que essa não se confunde com o mundo físico, pois o tempo é uma criação e um sentimento humano, produto das relações sociais. Logo, a divisão pormenorizada do tempo pelo historiador torna-se compreensivel e racional, no momento em que esse se põe a categorizar diferentes épocas a partir de similitudes entre elas, muito embora essa divisão possa ser discrepante entre eles.

Nesse entremeio dos aspectos da temporalidade, temos em seu âmago a instância do passado, do presente e do futuro, que em nossa época é tão natural, mas que há tempos, suas imbricadas relações são objetos de reflexão. Então, o que podemos falar que significam essas três instâncias? Temos a discorrer que no momento em que o presente do instante agora já é passado, o que se vislumbra em um piscar de olhos é o futuro daquele mesmo instante que agora já é passado. Essa resposta nos apresenta questões pertinentes e inexoravelmente atreladas à temporalidade do estudo da história. E, sobre este plano, autores como Koselleck (2006) e Hartog (2015) trazem em suas obras questões que remetem à discussão dessa imbricada relação entre essas instâncias temporárias, podemos citar conceitos como "espaço de experiências e horizonte de expectativas" e "presentismo", respectivamente. Enfim, para o historiador é relevante perceber que dentro de uma mesma sociedade, existem diversas compreensões sobre a forma de como essas instâncias se relacionam, ou seja, o modo como essas sociedades (ou mesmo grupos menores) percebem essa conexão de temporalidade entre o passado, o presente e o futuro.

O segundo ponto trata da duração. A noção do termo duração na historiografia moderna fora baseada não em questões cronológicas do tempo, e sim, relativo ao movimento e a permanência do atual para o novo, e nesse sentido, o tempo "é sentido ou percebido subjetivamente pelo ser humano, e não meramente um tempo cronométrico" (BARROS, 2014, p. 247), a partir desse olhar, podemos visualizar alguns aspectos relativos ao termo duração. A princípio destacaremos o aspecto relativo à cisão entre o tempo cronológico e o tempo de duração, tendo em vista que não é necessariamente cronológica essa duração e sim, de acordo com questões tidas pelo tempo interno, onde o homem é fazedor dessas ações, uma vez que independemente das passagens do tempo cronológico. Outro aspecto relevante ao termo duração, é que a velocidade de um determinado acontecimento, pode ser lenta ou rápida, a depender daquele que a observa, considerando para isso, as frações de fatos que ocorrem no(e) ao redor do objeto, para a partir de tal, essa velocidade ser mensurável. Por meio dessa mensuração da velocidade, pode-se ter a noção de que mudanças podem estar próximas ou ao invés disso, a permanência é notória e persistente no objeto observado. 
Também como aspecto da duração, temos a sociedade a qual está inserida a observação. Nesse contexto, é relevante destacar a multiplicidade de questões relativas que estão inseridas em um grupo ou em uma sociedade inteira, a qual pode observar um mesmo objeto com durações variáveis, tendo em vista, a heterogeneidade e a complexidade existentes na sociedade na qual o objeto de observação está inserido. E sob esse pensamento de sociedade complexa e levando em conta que essas são formadas por individuos heterogêneos, podemos deduzir que essa heterogeneidade pode ser aplicada a todas elas, reafirmando, assim, que o mesmo objeto pode ter durações variáveis dentro de uma mesma sociedade. E por consequência a isso, até mesmo os campos da atividade humana por também serem formados por individuos heterogêneos, também podem sob um mesmo objeto responderem com durações variáveis dentro de seu próprio campo. De forma mais simples e por meio de exemplo, podemos pensar na duração do tempo que se dispende ao se realizar uma ação com prazer recreacional e outra na qual o sofrimento ou a mesmice lhe é posta em absoluto, percebe então que mesmo havendo tempos cronológicos iguais para as duas ações, a segunda tende a ser considerada aquela na qual o tempo se move mais pausadamente.

O terceiro e último ponto trata do processo histórico. Para Barros (2014) a percepção de processo histórico se dá através do descrever, entender e narrar por meio de um encadeamento de eventos históricos que se interligam, e como isso, possibilita entender a conjuntura estabelecida ali através dos laços constituídos. Enfim, de forma bem simplória, consideramos o processo histórico sendo o conjunto das sucessões dos eventos históricos. Dessa forma, podemos citar, por exemplo, uma colcha de retalhos, sendo que cada retalho nos reporta a um evento histórico e a colcha completa nos daria a ideia de processo histórico. Nesse ponto, não buscaremos apenas tratar sobre definições de processo histórico, mas também, sobre conceitos que o rodeiam - ou que pelo menos, os consideramos mais correlacionados a esse, a saber:
a) evento (fato histórico);
b) devir;
c) continuidade e ruptura.

O primeiro destaque é a percepção de evento ou fato histórico. Como já fora dito que processo histórico é o conjunto de eventos históricos, mas então, o que viria a ser esses eventos/fatos históricos? A principio nortearemos que o evento histórico só o é, por ação direta ou indireta do sujeito histórico, que é o homem. E para exemplificar o que seria fato histórico, Carr (1996) discorre que, em um sentido de senso comum, são fatos que se estabelecem como espinhas dorsais da história, no entanto, para o historiador, o evento histórico deve ser observado sob dois aspectos: o primeiro trata da questão do tempo e do lugar ao qual ocorreu o evento; e o segundo, é a forma na qual o historiador irá se debruçar sobre esse objeto de estudo, pois o evento histórico fala através do historiador.

Temos então, que é o historiador aquele que de certa forma estabelece os fatos que serão postos à tona, a sua ordem e contexto, e assim cabe a ele decidir, por exemplo, o porquê de César atravessar o Rubicão e isso ser um fato histórico, ao passo que "a travessia do Rubicão, por milhões de outras pessoas antes ou desde então, não interessa a ninguém em absoluto" (CARR, 1996, p. 47). E, para complementar, citaremos Schaff (1995) quando estabelece uma distinção entre um fato qualquer que aconteceu no passado com um evento, ao qual pode ser considerado histórico devido sua importância à ciência da história, ou seja, não é qualquer fato que é histórico. E para se fazer essa mensuração, o historiador deve se basear no critério de valor que este fato apresenta dentro de um processo histórico, pois "a despeito das aparências e das convicções correntes, os fatos históricos não são um ponto de partida, mas um fim, um resultado" (1995, p. 307).

A partir do pensamento apresentado de Carr (1996) e Schaff (1995), o que se depreende dele? Podemos considerar que avaliar os fatos históricos, é um contínuo trabalho interpretativo para o historiador por meio de um diálogo com o tempo passado. Em vista a isso, não se pode considerar 
que sejam apresentados de forma incontaminada, uma vez que por ser ação interpretativa do historiador, ele o traz, a partir do contexto que lhe é apresentado. E a partir de tal, lança-o como fato histórico, levando-se em conta também, o contexto e as relações que o permeavam, e que isso, encadeará mais elos na conjuntura do processo histórico. De outro modo, o acontecimento será relegado ao esquecimento. Também deve-se destacar que, como o fato histórico é elevado ou descartado pelo historiador, é possivel que sob um mesmo acontecimento haja discordâncias. Isso ocorre porque o historiador utiliza o seu trabalho interpretativo do objeto como ferramenta de mensuração do que é ou não é fato histórico.

É importante realçar que determinados fatos históricos possam ser relevantes apenas a determinado lugar ou mesmo a um grupo restrito de individuos, podemos exemplificar da seguinte forma: se de um lado, as duas grandes guerras mundiais são inexoravelmente fatos históricos de interesse para os mais diversos campos da atividade humana, de outro, a criação do Instituto Nacional dos Surdos no século XIX no Brasil - um marco para a educação inclusiva -, no âmbito da física quântica, pouco tem relevância. Outro ponto a ser destacado a partir das ponderações dos autores, é que um acontecimento não seria identificado ou elevado a fato histórico se esse não estiver pautado no conhecimento histórico científico, onde a teoria apoia essa decisão. Assim sendo, o fato histórico seria construido através de diálogo entre os vestígios - que são documentos que apresentam sinais que possibilitam ao historiador (re)construir a história - e a teoria, apesar da interpretação do historiador ter grande peso. Os vestígios independentemente de sua origem devem ser avaliados pelo historiador, a fim de se verificar sua veracidade, para a partir disso, admiti-lo como fonte crivel ao fato histórico.

Com base nesses argumentos, descrevemos que o fato histórico é um acontecimento de relevância para a história, baseado na teoria e na veracidade dos vestígios através da interpretação do historiador. E que esse fato histórico será encadeado por outros fatos que o circunvizinham para completude do processo histórico ao qual está vinculado, uma vez que esse fato histórico é relevante para a compreensão do passado, do presente e quiçá como vislumbre para o futuro.

O segundo destaque é o que trata do termo devir. O termo devir é relevante para a história no instante em que denota mudança e transformação constante. Japiassú e Marcondes (2008) destacam o sentindo do devir sob alguns direcionamentos. Para eles, na filosofia aristotélica-escolástica, o devir não é nada além da passagem de determinado estado devido à influência do ato que ocasionou esse devir. De outro modo, em Hegel, o devir é a síntese dialética do ser e do não ser, pois, tudo o que existe é temporal e, assim, esse pode ser findado acarretando por si só, um devir com a sua futura inexistência. No pensamento de Gregório (2020), devir é posto como um problema desde os tempos pré-socráticos em Parmênides e Heráclito, pois tudo está sujeito a uma metamorfose perpétua das coisas que evoluem, de acordo com os ciclos que consolidam o enfrentamento dos contrários. E, por fim, para Deleuze e Guattari (1997), o devir se estabelece a partir das formas existentes dos sujeitos e de seus campos de atuação aos quais instituem relações de "movimento e repouso, de velocidade e lentidão, as mais próximas daquilo que estamos em vias de devir, e através das quais devimos. É nesse sentido que o devir é o processo do desejo" (DELEUZE; GUATTARI, 1997, p. 67).

A partir desses pensamentos, consideramos o sentido de devir como sendo uma transição contínua de determinado estado ao seu sentido contrário, muito embora não deva ser pensado como desordenado, uma vez que é nele onde as fronteiras são permeadas pelos entes que estão inseridos naquele ir e vir contínuo. Pensando dessa forma o devir se assenta pelo movimento, porém sem ser necessariamente de forma abrupta - onde o claro encontra o escuro ou o dia encontra a noite - mas em alusão ao dia em seu decurso natural de ordenanças, começando pelo florescimento da manhã e que se fortalece na tarde e aos poucos vem à noite, se sucedendo pelo escuro da madrugada e, enfim, o ciclo da manhã se renova. 
Em outras palavras, o devir é o que vai chegar, é o tornar-se-á, o transformar-se-á, o contínuo movimento e a progressiva e permanente mutação.

Outro aspecto do devir, o estabelece como ponto inicial de uma trajetória qualquer e seu destino final, nesse caso, torna-se um desconhecido no horizonte, tendo em vista - se não tenha sido um fato histórico já passado e consolidado - seus resultados podem ser imprevistos, dando em conta sua singularidade e seu ponto final ser futuro, uma incógnita e, quem sabe, uma quimera, uma utopia. No caso do historiador, o cuidado com o devir se pauta sempre em fundamentá-lo no método científico, sob o risco de o devir vislumbrado não representar a realidade, e sim a sua própria vontade do historiador frente a um acontecimento. Ademais, o devir traz a necessidade do ser diferente, pois em um estado único é impossivel haver devir, já que ele surge a partir da diferença, do novo, no menor que faz esse movimento dentro de um estado estabelecido em harmonia. Assim, o devir não surge em um cenário mais do mesmo, pois é estabelecido por uma pequena diferença dentro de uma maioria homogeneizada e a partir de tal, essa pequena diferença passa a ser mover e mover o todo, fazendo com que ou se finde ou cresça e possa, com isso, tornar-se de fato devir no processo histórico.

O terceiro destaque é o que trata de modo conjunto da continuidade e da ruptura. Muito embora saibamos que podem ser tratados de forma distinta, acreditamos que o cerne de ambos pode ser discutido de forma imbricada. Assim sendo, apenas do ponto de vista analítico se justificaria uma oposição entre os termos, pois segundo Duarte (2013) ruptura é uma descontinuidade, uma rápida mudança de curso previsivel dos acontecimentos, um corte nas relações e nos valores constituidos de determinada época, acompanhada de um salto rumo a uma conjuntura que se sobressairá sobre a de vanguarda. No entanto, é sob o fundamento da continuidade que se identifica essas rupturas, pois tendem a existir de forma mútua, e assim são dialeticamente unidas em um fluxo ao qual são forças motrizes do próprio movimento da história. A partir deste conceito de Duarte, podemos depreender algumas ponderações, pois ele trata a continuidade e ruptura dialeticamente, mas, também, como se fossem dois lados de uma mesma moeda. Assim, diz que a ruptura é a abrupta mudança com a finalidade de superar a conjuntura precedente, muito embora, o pano de fundo sempre esteja posto sobre o eixo temporal da continuidade, ou seja, uma não o é, sem a outra, tornando-as uma dialética unida e que movimentam e transformam os processos históricos ao qual se vinculam dentro de um contexto estrutural maior.

Outro conceito a ser apresentado é o de Lavigne (2018) ao significar em perspectiva histórica os dois termos. Esse autor discorre que a continuidade é utilizada no contexto da história para identificar padrões que persistem ao longo de gerações com fins identitários para perpetuação de determinado grupo. No que tange a ruptura, argumenta que essa define o rompimento/desaparecimento definitivo de certos elementos da história, e por conseguinte, uma substituição destes por novos elementos, sendo que, por vezes, contrários aos antigos vanguardistas. Ao referirmos a percepção de Lavigne sobre os dois termos, percebemos o aspecto da continuidade como um continuum harmônico temporal de determinado processo histórico, através da manutenção das ideias, características e valores, de dado contexto social. No caso da ruptura, o autor considera que essa cessa determinado ciclo, muito embora, por vezes, os novos elementos inseridos nesse contexto podem não ser necessariamente contrários aos ditos antigos, constituindo assim, apenas uma reformulação da velha forma de ser.

Nesse contexto de ruptura e de continuidade, Duarte (2013) nos lança a observação dos períodos de transição que se situam nas fronteiras desses processos históricos. Eles nos ajudam a clarificar os momentos havidos entre a continuidade e a ruptura, além do mais, se estabelece nesse contexto temporal a vivência entre os dois mundos simultaneamente, daquele que está se esvaindo para o que ainda não plenamente é. Pois, o contexto de vanguarda não foi determinantemente 
superado e sim, conserva-se em um movimento de transformação. Tendo em vista esse cenário, é difícil assinalar e taxar o exato momento dessa ruptura, pois a superação que se estabelece no contexto de transição implica também em "uma espécie de retorno ao passado que é, em cada etapa do desenvolvimento, reencontrado, mas superado e por isso mesmo aprofundado, liberado de suas limitações" (2013, p. 1).

Sob esses argumentos, nota-se, então, que os periodos de transição são campos abertos de enfrentamento das velhas contra as novas posições, entre o que foi, mas que ainda deseja resistir e o novo que se propõe a ser o protagonista. Muito embora, esse novo simplesmente não se impõe soberano sem mácula com o antigo, e sim, parte desse antigo para daí então, fincar suas condições para superação no campo em disputa. Por conta desta penumbra em que se encontram os períodos de transição, fixar a cronologia exata da continuidade ou da ruptura, é por vezes dificultoso.

O autor Barros (2011) faz uma relação entre a ruptura e a continuidade no contexto de período de tempo e devir, ao considerar que o tempo não se apresenta apenas como devir, mas também como uma extensão que perdura por determinado período e, esse tempo, ao ser comparado com outros anteriores, introduz ruptura ou retroalimenta continuidades. Nesse sentido, o contexto fronteiriço presente no devir histórico pode apontar a uma maior permanência, o que traria um maior senso de unidade de conjunto ou estrutura mais consolidada de determinada situação em certo periodo de tempo e, assim, um sentimento de continuidade. Outrossim, caso a mudança seja mais evidente o processo histórico tende a desencadear uma substituição mais enérgica do sistema de vanguarda daquele tempo e lugar, acarretando mudanças radicais. Isto posto, o historiador deve estar preparado a perceber nas complexidades dos vestígios que lhe são apresentados, esses movimentos fronteiriços do tempo e devir, na permanência da continuidade ou nas mudanças que a ruptura traz, muito embora "há autores que só percebem um caótico universo de descontinuidades na aventura humana" (BARROS, 2011, p. 251).

Também é destacado o devir existente entre os periodos de tempo, pois se de fato a continuidade despontar em detrimento a ruptura, a estrutura ${ }^{2}$ tende a permanecer, reforçando a sensação da harmonia estrutural, ou seja, a continuidade. De outro modo, o processo se inclina a reforçar a sensação da ruptura. E, por fim, realçamos o papel do historiador como o ator que vislumbra essa tendência à ruptura ou à continuidade dentro do processo histórico, que tal qual - metaforicamente - uma sanfona ao ser tocada pelo sanfoneiro, tende a aproximar ou distanciar esses termos, no contexto do sentido dialético ou trazê-lo à forma siamesa.

Como exemplos de ruptura e de continuidade a partir de obras consagradas, podemos citar Hobsbawm que em sua tetralogia das eras, trata dessa perspectiva. As obras são nomeadas da seguinte forma: A era das revoluções: 1789-1848 (HOBSBAWM, 2012) que versa sobre a passagem do Antigo Regime à Europa burguesa; $A$ era do capital: 1848-1875 (HOBSBAWM, 2012) que trata do capitalismo industrial e a consolidação da burguesia; A era dos impérios: 1875-1914 (HOBSBAWM, 2012) que apresenta o advento do imperialismo e conflitos entre grandes nações; e, a Era dos extremos: O breve século XX (19141991) (HOBSBAWM, 2012), que exibe fatos que se desenrolam desde o florescer até o declínio da revolução russa com o fim da União Soviética. Nesse cenário, percebe-se que a ruptura não se dá necessariamente a partir da virada do século, pois pela obra de Hobsbawm é necessário que haja um fato, um acontecimento marcante para tal. Isso é facilmente demonstrado em obras de autores sobre, por exemplo, a história do Brasil dividida entre Colônia, Império e República. A história americana, antes e depois da Revolução de 1776. A história inglesa a partir da união de-

2 No contexto do que Fernand Braudel (2007) chamaria de dialética das durações onde "as estruturas são elementos da longa duração, lentos, aparentemente imóveis, contínuos, permanentes; sustentam as oscilações cíclicas do tempo médio e exercem sobre os eventos uma contenção" (SEVALHO, 1997, p. 9). 
nominada Grã-Bretanha em 1707. Enfim, dentre outros exemplos similares em que a ruptura transcende a temporalidade, pois, é necessária uma ação do sujeito direta ou indireta para que essa ruptura se evidencie.

Desse modo, a partir desses conceitos e exemplos explanados podemos tomar parte de aspectos referentes à ruptura e à continuidade, e que esses termos são relevantes para compreendermos os processos históricos, tendo em vista que muito embora possam ser dialéticas, elas também podem ser siamesas. É interessante destacarmos, ainda, que a continuidade de determinadas práticas no processo histórico de curta ou longa duração, não significa ser essa boa ou má à sociedade na qual é imposta, em modo comparativo ao contexto de vanguarda, pois tiramos, por exemplo, o assassinato. Matar alguém está em leis e normas sociais como passivel de sanção do Oriente ao Ocidente e em todos os povos se acham referências para tal. Então, essa prática ser passivel de culpa é uma continuidade desde tempos antigos e, com isso, se procura manter a unidade e o controle da sociedade, muito embora haja situações de exceção à culpabilidade de quem o faz. Do outro lado, haver ruptura também não quer dizer que seja algo mau ou bom, tiramos, por exemplo, as que são realizadas em um curto espaço de tempo, como os golpes de estado que podem instituir no poder ditadores que farão bem ou mal para a sociedade à qual estão vinculados.

\section{Considerações finais}

Na intenção de apresentar as considerações finais a este trabalho, resgatamos o objetivo da investigação em curso que se propôs a discutir conceitos relacionados ao tempo, com fins a instigar diálogos que venham a se estabelecer a partir dessa perspectiva. Logo, por meio desta pesquisa multicampo, discutimos três características que são correlacionadas ao tempo: temporalidade que se perfaz através da percepção humana do compreender a conexão temporal existente entre o passado, o presente e o futuro; duração - essa não se pauta no tempo cronológico e sim, seu entendimento subjetivo é relativo ao movimento e à permanência do atual para o novo; e, por fim, processo histórico - que se pauta no conjunto das sucessões dos eventos históricos. Há de se destacar que o processo histórico é orbitado por conceitos inerentes a ele, como: evento/fato histórico - este não é um fato/acontecimento qualquer que aconteceu no passado e sim, é histórico devido sua importância à ciência da história; devir - é o momento de transição contínua de determinado estado ao seu sentido contrário, muito embora não deva ser pensado como desordenado, uma vez que é nele onde as fronteiras são permeadas pelos entes que estão inseridos naquele ciclo de ir e vir; continuidades e rupturas - estes conceitos são distintos, muito embora se complementem. Pois, se de um lado, a ruptura é um corte das relações presentes nos valores constituídos em determinado contexto, com fins a uma nova conjuntura que se sobressairá a de vanguarda, de outro, temos que a continuidade é a não ruptura já que é a permanência do status quo, em maior ou em menor grau, nos contextos fronteiriços advindos de um devir, que aponta a um novo modelo que poderá se impor. Enfim, a partir desses diálogos, acreditamos que se permitirá o alargar do arcabouço teórico para uma geração de historiadores que se formaram alheios à reflexão mais consistente sobre a temporalização no interior dos discursos históricos.

Ademais, como observações complementares advindas desse estudo destacamos que o estudo sobre o tempo não é recente, pois pensadores gregos da antiguidade já concebiam suas filosofias levando-se em conta esse objeto. Após eles, nos tempos do medievo e depois dele, autores de várias correntes e campos de estudo, também abordaram esse tema. Então, não é de se pasmar que também nos dias de hoje. dialogar e refletir sobre o tempo é uma questão pertinente. Também ressaltamos que o evento/ fato histórico não é uma criação por si mesma ou pelo senso comum, e sim o historiador é quem estabelece os fatos que serão postos à tona, a sua ordem e contexto, a partir da análise não apenas do fato em si - tempo e lugar - mas 
também através de critérios de valor que este fato se apresenta dentro do processo histórico. Esse critério deve ser permeado pelo diálogo entre os vestígios criveis levantados, a teoria e o próprio olhar interpretativo do historiador, com fins a ele mesmo ser a voz do evento histórico enquanto esse se apresenta como acontecimento relevante à ciência da história, tendo assim valor histórico para determinado lugar ou contexto local, regional ou mundial. Além desses, também é relevante destacar que os conceitos apresentados no processo histórico: devir, continuidade e ruptura, são pensamentos que de certa forma são complementares, mas ao mesmo tempo são antagônicos e se digladiam entre si, no campo de estudo de cada atividade humana ou mesmo entre elas, com vistas a serem interpretadas pelos vencedores dessa disputa.

Dessa forma, entendemos que nossos resultados derivados das discussões realizadas a partir do contexto desta pesquisa, corroboram com outras que partem do pressuposto que o diálogo acerca dos conceitos que permeiam a questão do tempo são relevantes para contribuir em debates e reflexões por estudantes, pesquisadores da história, tanto em aspectos teóricos quanto empíricos que se fundamentam nesse objeto, uma vez que essa temática é atual, pertinente e está presente em diversos campos da atividade humana.

Portanto, discutir conceitos relacionados ao tempo é um desafio para o historiador. Dessarte, muito embora tenhamos alcançado os nossos objetivos propostos para este recorte investigativo, há questões que vão além das perspectivas aqui discutidas pois existe todo um panorama que passa pela própria formação do pesquisador-historiador com vistas a esse ter uma teoria sólida e um olhar interpretativo acurado dos vestígios que lhe são apresentados. E, além desta, outras questões podem ser irradiadas por meio desse objeto de estudo que é o tempo.

\section{Referências}

AGOSTINHO, S. Confissões. Porto: Livraria Apostolado da Imprensa, 1955. Disponivel em: https://sumateologica. files.wordpress.com/2009/07/santo_agostinho_-_confissoes.pdf. Acesso em: 20 maio 2020.
AQUINO, T. D. Compêndio de Teologia. Tradução e Notas de D. Odilão Moura. São Paulo: Presença Edições, 1977. Disponivel em: https://efosm. files.wordpress. com/2013/02/compc3aandio-de-teologia-santo-tomcza1s-de-aquino.pdf. Acesso em: 20 maio 2020.

BACHELARD, G. A intuição do instante. Campinas: Verus editora, 2007

BARROS, I. C. D. R. No Limite do tempo. Rev. Estud. Lacan, Belo Horizonte, v. 3, n. 4, 2010. Disponivel em: http:// pepsic.bvsalud.org/scielo.php?script=sci_arttext\&pi$\mathrm{d}=\mathrm{S} 1983=07692010000100006-\& \mathrm{lng}=$ pt\&nrm=iso\&tlngpt. Acesso em: 19 maio 2020.

BARROS, J. D. Teoria da História - Os primeiros Paradigmas: Positivismo e Historicismo. Petrópolis: Editora Vozes, 2011. v. 2.

BARROS, J. D. A historiografia e os conceitos relacionados ao tempo. Dimensões, Vitória, ES, v. 32, p 240-266, 2014.

BÍBLIA. In: Biblia On-Line. [S. I.], 2020. Eclesiastes 3 Disponivel em: https://www.bibliaonline.com.br/acf/ ec/3. Acesso em: 20 maio 2020.

BLOCH, M. Apologia da História, ou, O ofício de historiador. Rio de Janeiro: [s. n.], 2001.

BORGES, J. L. Cinco visões pessoais. Tradução de Maria Rosinda Ramos da Silva. Brasília: Universidade de Brasilia, 1987.

BRAUDEL, F. Escritos sobre a História. Tradução de Jacob Guinburg e Tereza Cristina Silveira da Mota. São Paulo: Perspectiva, 2007.

BRECHT, B. Poemas 1913 - 1956. Seleção e tradução de Paulo César de Souza. 6. ed. São Paulo: Editora 34, 2006. Disponivel em: http://ciml.250x.com/archive/communists/brecht/spanish/bertolt_brecht___100_textos.pdf. Acesso em: 23 maio 2020.

CARR, E. H. O que é história. Tradução de Lúcia Mauricio de Alvarenga. 7. ed. São Paulo: Paz e Terra, 1996. Disponivel em: file:///D:/Downloads/carr_que_e_historia. pdf. Acesso em: 23 maio 2020.

COELHO, J. G. Ser do Tempo em Bergson. Interface - Comunic., Saúde, Educ., Botucatu, SP, v. 8, n. 15, p. 233-246, mar./ago. 2004.

DELEUZE, G.; GUATTARI, F. MIL PLATÔS. Capitalismo e Esquizofrenia. Coordenação da tradução Ana Lúcia de Oliveira. 1. ed. São Paulo: Editora 34, 1997. v. 4. Disponível em: http://escolanomade.org/wp-content/downloads/deleuze-quattari-mil-platos-vol4.pdf. Acesso em: 23 maio 2020

DUARTE, C. A dialética entre permanência e ruptura nos processos de transformação do espaço. In: Cristóvão1. [S. /], 2013. Disponivel em: https://cristova01.wordpress. $\mathrm{com} / 2010 / 08 / 01 / a-d i a l e t i c a-e n t r e-p e r m a n e n c i a-e-$ -ruptura-nos-processos-de-transformacao-do-espaco. Acesso em: 24 maio 2020.

GALILEI, G. Duas Novas Ciências. Tradução de Letizio Mariconda e Pablo R. Mariconda, Rio de Janeiro: Museu de Astronomia e Ciências Afins. 2. ed. São Paulo: Nova Stella, 1988. [original de 1638]. 
GHISOLFI, E. S. Sobre a Evolução Histórica do Conceito de Tempo e uma Investigação do seu Significado entre Estudantes de Diferentes Niveis de Escolaridade. 2008. Monografia (Graduação em Licenciatura em Física) Pontifícia Universidade Católica do Rio Grande do Sul, Porto Alegre, 2008.

GIL, A. C. Como elaborar projetos de pesquisa. 4. ed. São Paulo: Atlas, 2002

GREGÓRIO, S. B. Devir. In: Dicionário de Filosofia. IS. I.], 2020. Disponivel em: https://sites.google.com/ view/sbgdicionariodefilosofia/devir. Acesso em: 24 maio 2020

HARTOG, F. Regimes de historicidade: presentismo e experiências do tempo. Belo Horizonte: Autêntica, 2015

HOBSBAWM, E. J. E. A era das revoluções: 1789-1848. São Paulo: Paz \& Terra, 2012.

HOBSBAWM, E. J. E. A era do capital: 1848 - 1875. São Paulo: Paz \& Terra, 2012.

HOBSBAWM, E. J. E. A era dos impérios: 1875 - 1914. São Paulo: Paz \& Terra, 2012.

HOBSBAWM, E. J. E. Era dos extremos: O breve século XX - 1914-1991. São Paulo: Paz \& Terra, 2012.

JAPIASSÚ, H.; MARCONDES, D. Dicionário Básico de Filosofia. 5. ed. Rio de Janeiro: Zahar, 2008. Disponivel em: http://raycydio.yolasite.com/resources/dicionario_de_filosofia_japiassu.pdf. Acesso em: 20 maio 2020.

KANT, I. Crítica da Razão Pura. Tradução de Valério Rohden e Udo Baldur Moosburger. São Paulo: Abril Cultural, 1980. (Coleção "Os Pensadores").

KOSELLECK, R. Futuro Passado. Contribuição à Semântica dos Tempos Históricos. Tradução de Wilma Patricia Mass e Carlos Almeida Pereira. Rio de Janeiro: PUC-Rio, 2006.

LAVIGNE, N. C. B. Na perspectiva histórica, o que significa permanência e ruptura? In: Indagação. [S. I.], 2018. Disponivel em: https://WwW.indagacao.com.br/2018/04/ na-perspectiva-historica-o-que-significa-permanencia-e-ruptura.html. Acesso em: 24 maio 2020.

MARTINS, A. F. P. Concepções de estudantes acerca do conceito de tempo: uma análise à luz da epistemologia de Gaston Bachelard. 2004. Tese (Doutorado em Educação) - Faculdade de Educação, Universidade de São Paulo, São Paulo, 2004

NEWTON, I. Principia: Principios Matemáticos de Filosofia Natural. Tradução de Trieste Ricci et al. São Paulo: Nova Stella, 1990. v. 1.

NORBERT, E. Sobre o tempo. Tradução de Ribeiro V. Rio de Janeiro: Jorge Zahar, 1998.

PIETTRE, B. Filosofia e Ciência do Tempo. Tradução de Maria Antonia Pires de C. Figueiredo. Bauru: EDUSC, 1997.

PLATÃO. Timeu e Critias ou A Atlântida. Tradução de Noberto de Paula Lima. São Paulo: Hemus, 1981.
RAHMEIER, A. H. P. O que é tempo histórico. In: Faculdades Integradas de Taquara - FACCAT. 2020. Disponivel em: https://www2.faccat.br/portal/sites/default/ files/O\%20QUE\%20E\%2OTEMPO\%2OHISTORICO.pdf. Acesso em: 25 maio 2020.

SCHAFF, A. História e Verdade. 6. ed. São Paulo: Martins Fontes, 1995.

SEVALHO, G. Tempos históricos, tempos físicos, tempos epidemiológicos: prováveis contribuições de Fernand Braudel e Ilya Prigogine ao pensamento epidemiológico. Cad. Saúde Pública, Rio de Janeiro, v. 13, n. 1, p. 7-20, jan. 1997. Disponível em: http:// WWW.scielo.br/scielo.php? script=sci_arttext\&pi$\mathrm{d}=$ S0102-311X1997000100002\&lng=en\&nrm=iso. Acesso em: 24 maio 2020

\section{Cristina de Cássia Pereira Moraes}

Doutora em História das Ideias pela Universidade Nova de Lisboa (UNL), em Lisboa, Portugal; mestre em História pela Universidade Federal de Goiás (UFG), em Goiânia, GO, Brasil; professora associada do Departamento de História da Universidade Federal de Goiás (UFG), em Goiás, GO, Brasil.

\section{João Ferreira Sobrinho Junior}

Doutorando em História pela Universidade Federal de Goiás (UFG), em Goiânia, GO, Brasil; mestre em Ciência da Computação pela Universidade Federal de Pernambuco (UFPE), em Recife, PE, Brasil; técnico em Assuntos Educacionais da Universidade Federal de Goiás (UFG), em Goiânia, GO, Brasil.

\section{Endereço para correspondência}

Cristina de Cássia Pereira Moraes/ João Ferreira Sobrinho Junior

Universidade Federal de Goiás

Faculdade de História

Av. Esperança, $\mathrm{s} / \mathrm{n}$

Chácaras de Recreio Samambaia, 74690-900

Goiânia, GO, Brasil

Os textos deste artigo foram revisados pela Poá Comunicação e submetidos para validação do(s) autor(es) antes da publicação. 